\title{
Impedance Estimation Read-out System for Biomedical Sensors
}

\author{
Guan-Ru Chen ${ }^{1}$, Tsung-Yi Tsai ${ }^{1}$, I-Yu Huang ${ }^{1}$, Yu-Cheng Lin ${ }^{2}$, and Chua-Chin Wang ${ }^{1+}$ \\ ${ }^{1}$ Department of Electrical Engineering, National Sun Yat-Sen University, Kaohsiung, Taiwan 80424 \\ ${ }^{2}$ Department of Engineering Science, National Cheng Kung University, Tainan, Taiwan 70101
}

\begin{abstract}
An impedance estimation read-out system for biomedical sensors to detect cancer biomarkers using TSMC $0.18 \mu \mathrm{m}$ mixed signal CMOS process is proposed in this investigation. Without disadvantages such as long detection time, and high cost of conventional methods, this system integrates bio-electrical impedance analysis (BIA) technique with a read-out system is a solution of high accuracy of the least impedance $(<0.292 \%)$ and phase error $(<0.1 \%)$ in the widest frequency range $(10 \mathrm{~Hz}-2 \mathrm{MHz})$.
\end{abstract}

Keywords: impedance estimation, biomedical sensor, read-out system, BIA, tumor marker, ELISA, RIA.

\section{Introduction}

Cancer is one of the top causes for death in modern society. More and more people are suffered from cancer than ever. However, according to the research of biomedical immunity society, cancer can be detected from human blood or urine by sensing the concentration of tumor markers. Tumor markers, e.g., CEA, PSA, AFP, ALP, are all proteins generated from the cells in human bodies, regardless the cells are normal or not. Therefore, detecting the concentration of specific tumor marker is the first step of curing. Today, two main methods to detect tumor marker concentration are 'Enzyme linked immune-sorbent assay' (ELISA) [1-4] and 'Radioimmunoassay' (RIA) [5-7]. These two methods are based on optical theory, which have some issues on reagents consumption ( $>25 \mathrm{uL} /$ well), long detection (120-150 min), and cost ( $>$ NT 300,000). By contrast, 'Bio-electrical impedance analysis' (BIA) [8] is a better solution to attain real-time, low cost, low reagents consumption, and portable analysis, where BIA relies on the detection of electrical characteristics (impedance, admittance, phase, and frequency response) of biomedical sensors. Besides, the read-out system for BIA technique is needed, which will be disclosed below.

\section{Impedance Estimation Read-out System Design}

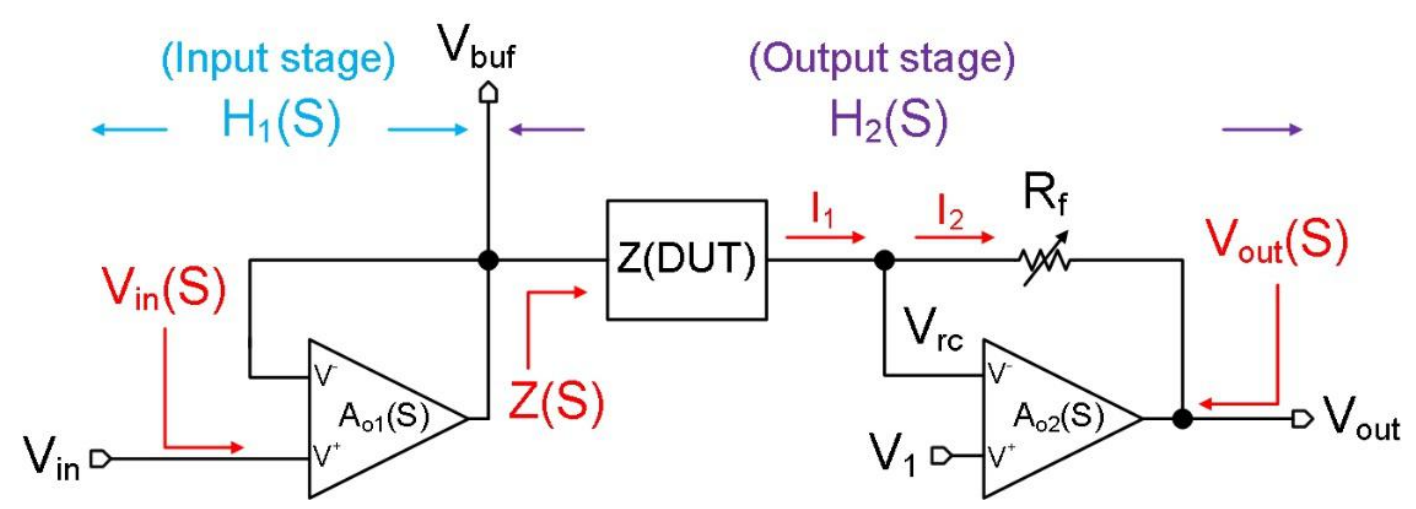

Fig. 1: Block diagram of proposed impedance estimation read-out system.

\footnotetext{
+ Corresponding author. Tel.: +886-75254149; fax: +886-75254112.

E-mail address: ccwang@ee.nsysu.edu.tw.
} 


\subsection{Overall circuit}

Fig. 1 shows the block diagram of the proposed impedance estimation read-out system, consisting of 2 OPAs, 1 VR (Variable Resistor, $\mathrm{R}_{\mathrm{f}}$ ), and 1 DUT (Device Under Test). $\mathrm{V}_{\text {in }}$ is the input sinusoid testing signal with various frequency and $2 \mathrm{~V}$ amplitude. OPA1 is a unit gain buffer, which provides high input impedance and low output impedance to reject the loading effect from the testing signal. DUT is the biosensor, where its impedance will be changed according to the frequency of the input signal. As for $\mathrm{R}_{\mathrm{f}}$, it will be a variable resistor to make $\mathrm{V}_{\text {out }}$ adjustable in Output stage (inverting amplifier) to avoid distortion.

The transfer function of $\mathrm{H}_{1}(\mathrm{~S})$ and $\mathrm{H}_{2}(\mathrm{~S})$ are derived in Eqn. (1) and Eqn. (2), where $\mathrm{A}_{\mathrm{ol}}(\mathrm{S})$ and $\mathrm{A}_{02}(\mathrm{~S})$ are the open-loop gains of OPA1 and OPA2, respectively. Therefore, the transfer function of the overall system is summarized in Eqn. (3). Then, as $A_{o 1}(S)$ and $A_{02}(S)$ are far greater than 1, the frequency response of DUT can be simplified as Eqn. (4). As we can see the last part of Eqn. (4), which is the major error of the system, can be ignored when $\mathrm{A}_{\mathrm{o} 2}(\mathrm{~S})$ is far greater than $\mathrm{R}_{\mathrm{f}}$. However, according to the bode plot of OPA, the error will increase when it comes to high frequency region. On the other hand, high gain will lead to limited bandwidth, which is also a key factor to be considered in designing such a system. Therefore, only OPA with appropriate gain and bandwidth can achieve the minimum error in the designated frequency region of the selected sensors.

$$
\begin{gathered}
\mathrm{H}_{1}(\mathrm{~S})=\frac{\mathrm{V}_{\text {buf }}(\mathrm{S})}{\mathrm{V}_{\text {in }}(\mathrm{S})}=\frac{\mathrm{A}_{\mathrm{o} 1}(\mathrm{~S})}{1+\mathrm{A}_{\mathrm{o} 1}(\mathrm{~S}) \times \beta_{1}(\mathrm{~S})} ; \beta_{1}(\mathrm{~S})=1 \\
\mathrm{H}_{2}(\mathrm{~S})=\frac{\mathrm{V}_{\text {out }}(\mathrm{S})}{\mathrm{V}_{\text {buf }}(\mathrm{S})}=(-1) \times \frac{\mathrm{A}_{\mathrm{o} 2}(\mathrm{~S}) \times \mathrm{R}_{\mathrm{f}}}{\mathrm{Z}(\mathrm{S})+\mathrm{R}_{\mathrm{f}}+\mathrm{A}_{\mathrm{o} 2}(\mathrm{~S}) \times \mathrm{Z}(\mathrm{S})} \\
\frac{\mathrm{V}_{\text {out }}(\mathrm{S})}{\mathrm{V}_{\text {in }}(\mathrm{S})}=\mathrm{H}_{1}(\mathrm{~S}) \times \mathrm{H}_{2}(\mathrm{~S})=(-1) \times \frac{\mathrm{A}_{\mathrm{o} 1}(\mathrm{~S}) \times \mathrm{A}_{\mathrm{o} 2}(\mathrm{~S}) \times \mathrm{R}_{\mathrm{f}}}{\left[1+\mathrm{A}_{\mathrm{o} 1}(\mathrm{~S}) \times \beta_{1}(\mathrm{~S})\right] \times\left[\mathrm{Z}(\mathrm{S})+\mathrm{R}_{\mathrm{f}}+\mathrm{A}_{\mathrm{o} 2}(\mathrm{~S}) \times \mathrm{Z}(\mathrm{S})\right]} \\
\mathrm{Z}(\mathrm{S})=(-1) \times \frac{\mathrm{V}_{\text {in }}(\mathrm{S}) \times \mathrm{A}_{\mathrm{o} 1}(\mathrm{~S}) \times \mathrm{A}_{\mathrm{o} 2}(\mathrm{~S}) \times \mathrm{R}_{\mathrm{f}}}{\mathrm{A}_{\mathrm{o} 1}(\mathrm{~S}) \times \mathrm{A}_{\mathrm{o} 2}(\mathrm{~S}) \times \mathrm{V}_{\text {out }}(\mathrm{S})}-\frac{\mathrm{R}_{\mathrm{f}}}{\mathrm{A}_{\mathrm{o} 2}(\mathrm{~S})}
\end{gathered}
$$

\subsection{DUT and RC equivalent circuit}
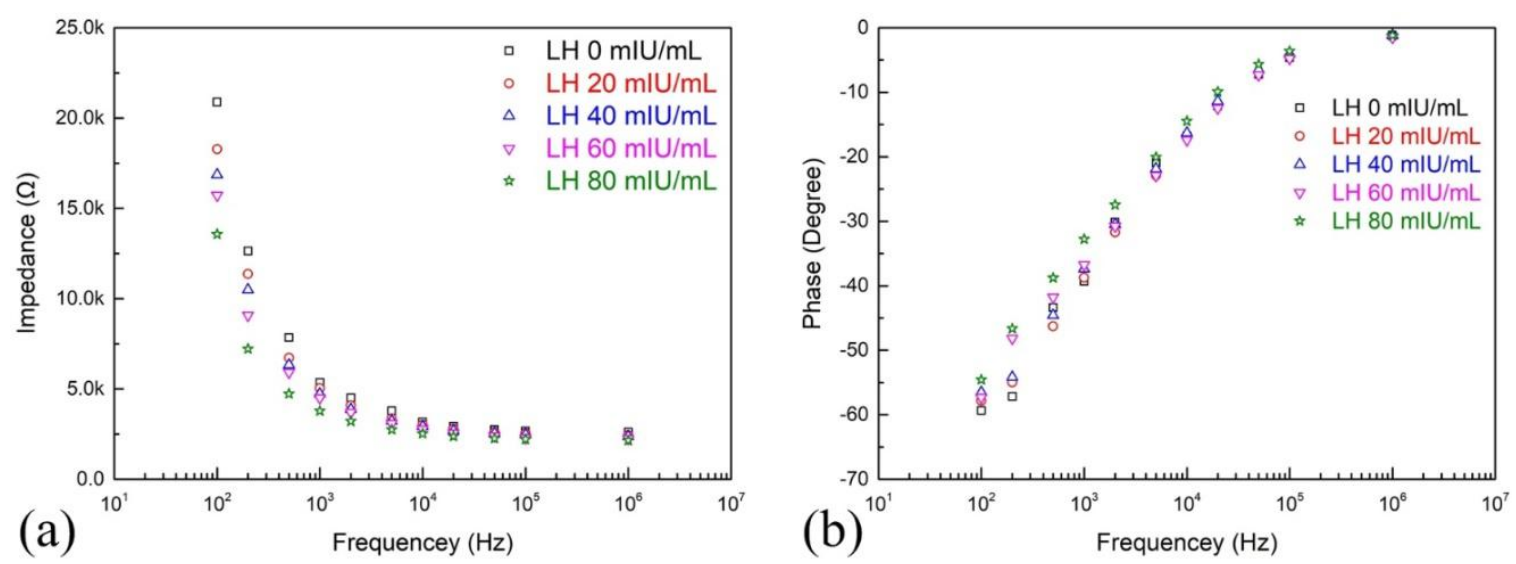

Fig. 2: (a) Impedance and; (b) phase analysis with various concentration by LCR meter.

Referring to Fig. 2 (a) and (b), it shows the measured results of impedance and phase by an LCR meter. This bio-sensor demonstrates different characteristics when various Luteinizing hormone (LH) concentrations are used. As for the impedance, it shows negative correlation with frequency, while the phase shows positive correlation with frequency on the contrary. Notably, the above test performs with designated frequency region from $100 \mathrm{~Hz}$ to $1 \mathrm{MHz}$.

However, in the circuit design step, an equivalent RC circuit is needed to establish the system. Therefore, as shown in Fig. 3 (a), a 3rd-order RC model is used to mimic the characteristic when LH concentration is 0 $\mathrm{mlU} / \mathrm{mL}$. The ideal impedance and phase of RC model is depicted in the red line of Fig. 3 (b), where the black line is the statistic of $0 \mathrm{mlU} / \mathrm{mL}$ for comparison. Notably, the aim of the RC model is to set up testing environment for the read-out system, but not the similarity between the RC model and the measurement results. 


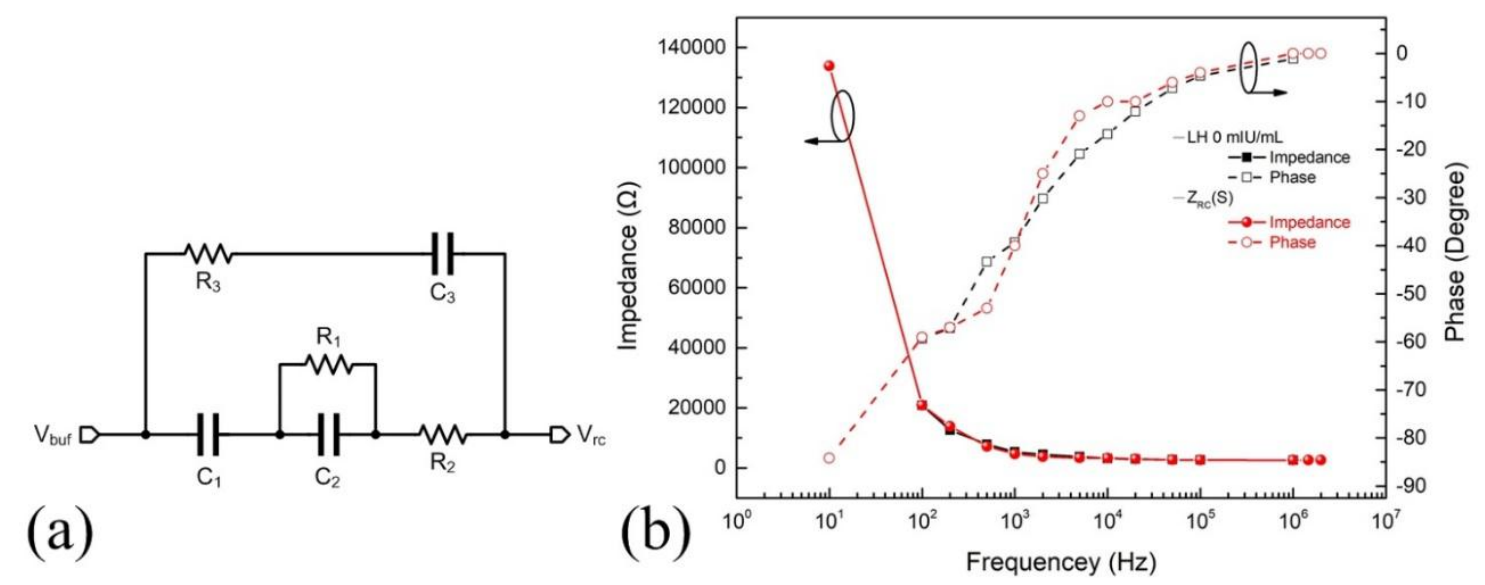

Fig. 3: (a) RC equivalent circuit, and (b) electrical characteristic comparison.

\section{Simulation Results}

In our system simulations, the designated frequency region is enlarged (10 Hz to $2 \mathrm{MHz}$ ) to ensure the reliability. Table I shows the worst case pre-layout and post-layout performance of the OPA. The worst case is at $2.97 \mathrm{~V}$, SS corner, and $0{ }^{\circ} \mathrm{C}$.

Table 1: OPA performance in pre layout and post layout simulation

\begin{tabular}{|c|c|c|c|c|c|c|c|}
\hline & $\begin{array}{c}\text { SR } \\
(\mathrm{V} / \mathrm{us})\end{array}$ & $\begin{array}{c}\text { DC gain } \\
(\mathrm{dB})\end{array}$ & $\begin{array}{c}\text { Phase margin } \\
(\text { degree })\end{array}$ & $\begin{array}{c}\text { GBW } \\
(\mathrm{MHz})\end{array}$ & $\begin{array}{c}\text { Output swing } \\
(\mathrm{V})\end{array}$ & $\begin{array}{c}\text { Input swing } \\
(\mathrm{V})\end{array}$ & $\begin{array}{c}\text { Max. power } \\
(\mathrm{mW})\end{array}$ \\
\hline $\begin{array}{c}\text { Pre-layout } \\
\text { simulation }\end{array}$ & 34.96 & 73.06 & 63.92 & 273.3 & $0.195-3.047$ & $0.253-3.263$ & $\begin{array}{c}8.608 \\
@ 2 \mathrm{MHz}\end{array}$ \\
\hline $\begin{array}{c}\text { Post-layout } \\
\text { simulation }\end{array}$ & 30.59 & 73.53 & 55.75 & 262.0 & $0.185-3.061$ & $0.252-3.241$ & $\begin{array}{c}7.653 \\
@ 2 \mathrm{MHz}\end{array}$ \\
\hline
\end{tabular}

The overall system simulations are revealed and tabulated in Fig. 4 and Table II. Referring to Fig. 4, black line is the ideal frequency response of the RC model. Red line and blue line are the results of prelayout and post-layout simulations, respectively. Table II tabulates the statistics and error of each frequency simulation. The worst case is at $2.97 \mathrm{~V}, \mathrm{SS}$ corner, and $0{ }^{\circ} \mathrm{C}$.

The proposed impedance calculation read-out system is realized using TSMC $0.18 \mu \mathrm{m}$ mixed signal CMOS process. Fig. 5 shows the layout of this prototype system on silicon, where the overall chip size is $758 \times 563 \mu \mathrm{m}^{2}$. Table III is the comparison with some prior works. Our work attains the widest frequency range, the least impedance and phase error.

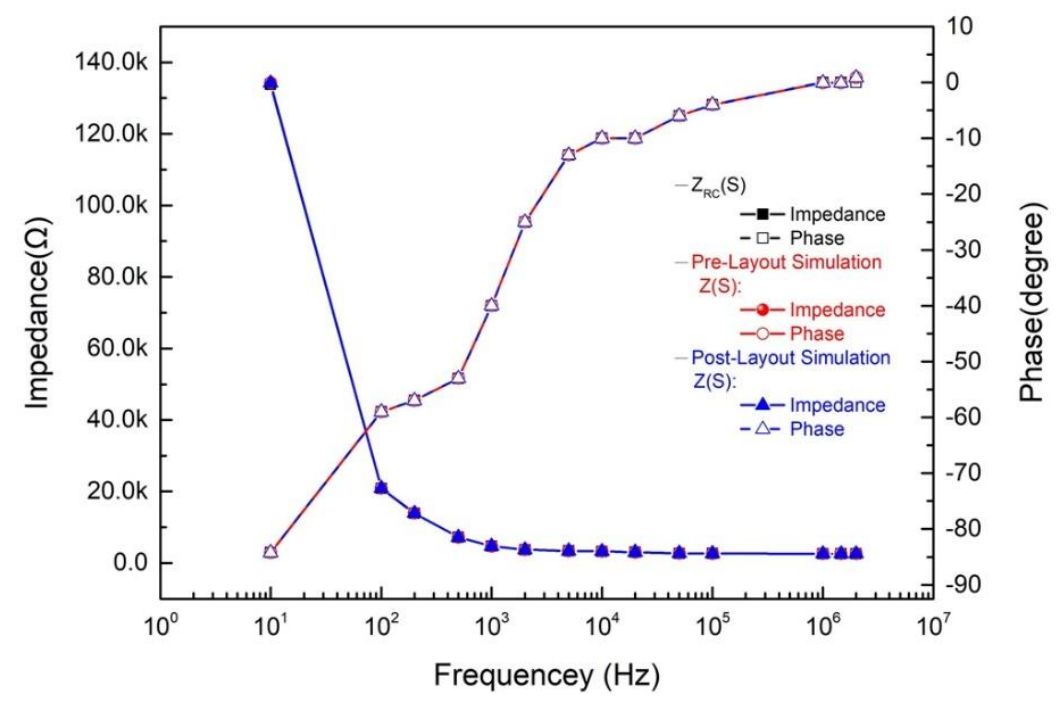

Fig. 4: Overall simulation results. 
Table 2: Overall simulation results

\begin{tabular}{|c|c|c|c|c|c|}
\hline \multirow{2}{*}{$\begin{array}{l}\text { Frequency } \\
\quad(\mathrm{Hz})\end{array}$} & & \multirow{2}{*}{$\begin{array}{l}\text { Pre-layout } \\
\text { simulation } \\
\mathrm{Z}(\mathrm{S})(\mathrm{k} \Omega)\end{array}$} & \multirow{2}{*}{$\begin{array}{l}\text { Post-layout } \\
\text { simulation }\end{array}$} & \multicolumn{2}{|c|}{ Worst-case error } \\
\hline & $\mathrm{Z}_{\mathrm{RC}}(\mathrm{S})(\mathrm{k} \Omega)$ & & & Impedance (\%) & Phase (\%) \\
\hline 10 & $133.868<-84.2^{\circ}$ & $134.205 \angle-84.2^{\circ}$ & $134.205<-84.2^{\circ}$ & 0.251 & 0 \\
\hline 100 & $20.876<-59^{\circ}$ & $20.936<-59^{\circ}$ & $20.936<-59^{\circ}$ & 0.287 & 0 \\
\hline 200 & $13.888 \angle-57^{\circ}$ & $13.920<-57^{\circ}$ & $13.920<-57^{\circ}$ & 0.230 & 0 \\
\hline 500 & $7.194 \angle-53^{\circ}$ & $7.189 \angle-53^{\circ}$ & $7.189 \angle-53^{\circ}$ & 0.069 & 0 \\
\hline $1 \mathrm{k}$ & $4.694 \angle-40^{\circ}$ & $4.698<-40^{\circ}$ & $4.698 \angle-40^{\circ}$ & 0.085 & 0 \\
\hline $2 \mathrm{k}$ & $3.731<-40^{\circ}$ & $3.738<-25^{\circ}$ & $3.738<-25^{\circ}$ & 0.187 & 0 \\
\hline $5 \mathrm{k}$ & $3.389<-13^{\circ}$ & $3.389 \angle-13^{\circ}$ & $3.389 \angle-13^{\circ}$ & 0 & 0 \\
\hline $10 \mathrm{k}$ & $3.246<-10^{\circ}$ & $3.246<-10^{\circ}$ & $3.246<-10^{\circ}$ & 0 & 0 \\
\hline $20 \mathrm{k}$ & $3.021<-10^{\circ}$ & $3.025 \angle-10^{\circ}$ & $3.025 \angle-10^{\circ}$ & 0.132 & 0 \\
\hline $50 \mathrm{k}$ & $2.732<-6^{\circ}$ & $2.740<-6^{\circ}$ & $2.740<-6^{\circ}$ & 0.292 & 0 \\
\hline $100 \mathrm{k}$ & $2.652<-4^{\circ}$ & $2.651<-4^{\circ}$ & $2.651<-4^{\circ}$ & 0.037 & 0 \\
\hline $1 \mathrm{M}$ & $2.617 \angle 0^{\circ}$ & $2.622 \angle-0.06^{\circ}$ & $2.622 \angle-0.06^{\circ}$ & 0.191 & N/A \\
\hline $1.58 \mathrm{M}$ & $2.617 \angle 0^{\circ}$ & $2.619 \angle-0.10^{\circ}$ & $2.622 \angle 0.89^{\circ}$ & 0.191 & N/A \\
\hline $2 \mathrm{M}$ & $2.617 \angle 0^{\circ}$ & $2.619 \angle 0.87^{\circ}$ & $2.619 \angle 0.86^{\circ}$ & 0.076 & $\mathrm{~N} / \mathrm{A}$ \\
\hline
\end{tabular}

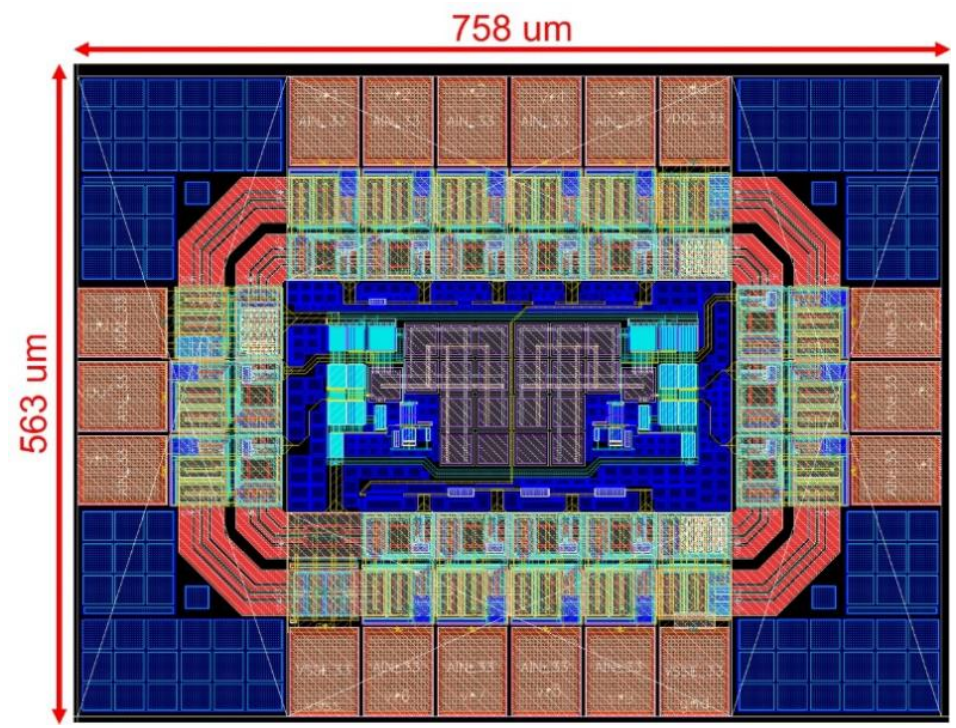

Fig. 5: Layout of the proposed read-out system.

\section{Conclusions}

This paper has demonstrated an impedance estimation read-out system with the widest frequency region, the least impedance and phase error, which is justified by Table III [9-11]. By integrating BIA technique with the read-out IC system, we find a better, more reliable, and quicker solution on rapid diagnostic test on cancer biomarkers. Notably, the investigation was partially supported by Ministry of Science and Technology, Taiwan, under grant MOST 106-2221-E-110-065- and MOST 106-2221-E-110-058-. The authors would like to express our deepest gratitude to CIC (Chip Implementation Center) in Taiwan, for the assistance of thoughtful chip fabrication. 
Table 3: Performance comparison

\begin{tabular}{|c|c|c|c|c|}
\hline & [9] & {$[10]$} & [11] & This work \\
\hline Year & 2015 & 2012 & 2010 & 2018 \\
\hline Publication & $\begin{array}{c}\text { Journal } \\
\text { Sensors and Actuator } \\
\text { B: Chemical }\end{array}$ & $\begin{array}{c}\text { Journal } \\
\text { Computers and } \\
\text { Electronics in } \\
\text { Agriculture }\end{array}$ & $\begin{array}{c}\text { Journal } \\
\text { Microelectronics }\end{array}$ & \\
\hline Implementation & Measurement & Measurement & Simulation & Simulation \\
\hline $\begin{array}{l}\text { Valid frequency region } \\
\qquad(\mathrm{Hz})\end{array}$ & $100-1 \mathrm{M}$ & $100-1 \mathrm{M}$ & $100-1 \mathrm{M}$ & $10-2 \mathrm{M}$ \\
\hline Impedance error & $\begin{array}{c}<250 \Omega \\
\text { (Eye Meas.) }\end{array}$ & $<4.96 \%$ & $<3.68 \mathrm{k} \Omega$ & $\begin{array}{c}<0.292 \% \\
(8 \Omega)\end{array}$ \\
\hline Phase error & $\begin{array}{l}\quad<10^{\circ} \\
\text { (Eye Meas.) }\end{array}$ & $<2.94^{\circ}$ & $<8.28^{\circ}$ & $<0.89^{\circ}$ \\
\hline
\end{tabular}

\section{Reference}

[1] R. M. Lequin, "Enzyme immunoassay (EIA)/enzyme-linked immunosorbent assay (ELISA)," Clinical Chemistry, vol. 51, no. 12, pp. 2415-2418, Sep. 2005.

[2] S. X. Leng, J. E. McElhaney, J. D. Walston, D Xie, N. S. Fedarko, and G. A. Kuchel, "ELISA and multiplex technologies for cytokine measurement in inflammation and aging research," Journal of Gerontology: Biological Sciences and the Journal of Gerontology: Medical Sciences, vol. 63, no. 8, pp.879-884, Oct. 2008.

[3] D. Limmathurotsakul, N. Chantratita, N. Teerawattanasook, K. Piriyagitpaiboon, A. Thanwisai, V. Wuthiekanun, N. P. J. Day, B. Cooper, and S. J. Peacock, "Enzyme-linked immunosorbent assay for the diagnosis of melioidosis: Better than we thought," Clinical Infectious Diseases, vol. 52, no. 8, pp.1024-1028, Jan. 2011.

[4] X.-X. Jiang, H.-Y. Shi, N. Wu, and M.-H. Wang, "Development of an enzyme-linked immunosorbent assay for diniconazole in agricultural samples," Food Chemistry, vol. 125, no. 4, pp. 1385-1389, Apr.2011.

[5] S .P. Musial, M. P. Duran, and R. V. Smith, "Analysis of solvent-mediated conformational changes of insulin by radioimmunoassay (RIA) techniques," Journal of Pharmaceutical and Biomedical Analysis, vol. 4, no. 5, pp. 589600, 1986.

[6] H. V. Webster, A. J. Bone, K. A. Webster, and T. J. Wilkin, "Comparison of an enzyme-linked immunosorbent assay (ELISA) with a radioimmunoassay (RIA) for the measurement of rat insulin, "Journal of Immunological Methods, vol. 134, no. 1, pp. 95-100, Nov. 1990.

[7] M. E. Goldberg and L. D.-Ohaniance, "Methods for measurement of antibody/antigen affinity based on ELISA and RIA," Current Opinion in Immunology, vol. 5, no. 2, pp. 278-281, 1993.

[8] R. F. Kushner and D. A. Schoeller, "Estimation of total body water by bioelectrical impedance analysis," American Journal of Clinical Nutrition, vol. 44, no. 3, pp. 417-424, Sep. 1986.

[9] H.-B. Ma, J.-H. Li, X. Cheng, and Arokia Nathan, "Heterogeneously integrated impedance measuring system with disposable thin-film electrodes," Sensors and Actuators B: Chemical, vol. 233, no. supplement C, pp. 77-82, Jan. 2015.

[10] C.-M. Lin, L.-H. Chen, and T.-M. Chen, "The development and application of an electrical impedance spectroscopy measurement system for plant tissues," Computers and Electronics in Agriculture, vol. 82, no. supplement C, pp. 96-99, Oct. 2012.

[11] A. Yúfera, and A. Rueda, "Design of a CMOS closed-loop system with applications to bio-impedance measurements," Microelectronics, vol. 41, issue 4, pp. 231-239, Apr. 2010. 